\title{
Last Concentration Normalized by Weight
}

National Cancer Institute

\section{Source}

National Cancer Institute. Last Concentration Normalized by Weight. NCI Thesaurus.

Code C92390.

The concentration corresponding to Tlast divided by the weight. 